\title{
Blended learning in situated contexts: 3-year evaluation of an online peer review project
}

\section{Running title: Blended learning in situated contexts: A 3-year evaluation}

\section{Dr Susan Bridges*}

Faculty of Dentistry, The University of Hong Kong

Prince Philip Dental Hospital, 34 Hospital Road, Sai Ying Pun, Hong Kong

Email: sbridges@hku.hk

\section{Dr Jeffrey WW Chang}

Faculty of Dentistry, The University of Hong Kong

Prince Philip Dental Hospital, 34 Hospital Road, Sai Ying Pun, Hong Kong

Email: jwwchang@hku.hk

\section{Dr Chun Hun CHU}

Faculty of Dentistry, The University of Hong Kong

Prince Philip Dental Hospital, 34 Hospital Road, Sai Ying Pun, Hong Kong

Email: chchu@hku.hk

\section{Dr Karen Gardner}

Nobel Biocare Oral Health Centre, The University of British Columbia

2151 Wesbrook Mall, Vancouver, BC V6T 1 Z3

Email: kgardner@dentistry.ubc.ca

Key words: dental education; e-learning ; peer review; learning outcomes; online learning; community of practice; operative techniques; evaluation; undergraduate education; clinical skills; situated learning 


\section{Abstract}

Background: Situated and socio-cultural perspectives on learning indicate the design of complex tasks supported by educational by technologies holds potential for dental education in moving novices towards closer approximation of the clinical outcomes of their expert mentors. A crossFaculty, student-centred, web-based project in Operative Dentistry was established within the Universitas 21 (U21) network of higher education institutions to support university goals for internationalisation in clinical learning by enabling distributed interactions across sites and institutions. This paper aims to present evaluation of one dental faculty's project experience of curriculum re-design for deeper student learning.

Methods: A mixed-method case study approach was utilised. Three cohorts of second-year students from a 5-year Bachelor of Dental Surgery (BDS) programme were invited to participate in annual surveys and focus group interviews on project completion. Survey data was analysed for differences between years using multivariate logistical regression analysis. Thematic analysis of questionnaire open responses and interview transcripts was conducted.

Results: Multivariate logistic regression analysis noted significant differences across items over time indicating learning improvements, attainment of university aims and the positive influence of re-design. Students perceived the inquiry-based project as stimulating and motivating; and building confidence in operative techniques. Institutional gaols for greater understanding of others and lifelong learning showed improvement over time. Despite positive scores, students indicated global citizenship and intercultural understanding were as conceptually challenging.

Conclusions: Establishment of online student learning communities through a blended approach to learning stimulated motivation and intellectual engagement thereby supporting a situated approach to cognition. Socio-cultural perspectives indicate that novice-expert interactions supported student development of professional identities. 


\section{Introduction}

New educational technologies are supporting innovative, effective and flexible curriculum models in clinical faculties. The goal of such innovations is to transform student learning experiences and to support future practitioners in their attainment of institutional learning outcomes and graduating competences. Initiatives in creating digital repositories have extended the resources available to staff and students. However, from a situated learning perspective, the design of complex tasks drawing on blended, distributed environments holds further promise in moving novices towards closer approximation of the clinical outcomes of their expert mentors. Situated approaches to learning (1) illustrate "how cognition is closely coupled to its social, material, and cultural context" (p. 302). The cross-institutional project aimed to enhance cognitive engagement through close attention to these three contexts from project conceptualisation, to website design and community building amongst participating faculty leaders and students.

The idea of blending different learning experiences has been in existence ever since humans started thinking about teaching and designing curricula; however, in the case of educational technologies this involves extensive curriculum redesign (2). One survey in higher education has indicated that $80 \%$ of all institutions and $93 \%$ of doctoral institutions offer hybrid or 'blended learning' courses (3). While researchers suggest that learning in the 2000s will always have an element of ' $e$ ' (4), its format remains an ongoing issue. While blended learning has been commonly defined as an integration of traditional face-to-face and online approaches to instruction, it is becoming increasingly evident that this is not sufficient (5). Where blended learning becomes an exercise involving technology as an add-on supplement to the traditional course much potential can be lost. The need for reconceptualising blended learning and redesigning pedagogical approaches is a recognised priority for medical education (6). Of particular relevance to this project evaluation is the concern that, in the blended learning endeavour, it is the pedagogy and the learning, not the actual technologies engaged that should be the focus of attention $(7,8)$.

In what follows, one particular international dental education initiative $(9,10)$ utilising a blended approach is described and one faculty's experience is evaluated as a case study. The aim of this paper is to explore how task-specific characteristics that contributed to the acquisition of disciplinary knowledge and skills and professional attributes could meet deeper approaches to 
learning. Specifically, this paper considers how students perceived the attainment of wider university learning outcomes and disciplinary knowledge and attitudes whilst developing clinical competencies (11).

\section{Curriculum re-design and blended learning in dentistry}

New resources and pedagogic approaches have emerged as clinical faculties globally have been re-designing and implementing outcomes- and competency-based models to prepare graduates to cope with the complexity of dealing with increased access to information and the constantly changing evidence underlying practice (12). Peer-reviewed digital repositories (see, for example MedEdPORTAL(13)) have leveraged the proliferation of in-house digital and other online materials to provide open-access medical and oral health teaching materials, assessment tools, and faculty development resources. Studies in dental education indicate various encouraging adoptions of educational technologies with:

- videos of clinical procedures improving performance in undergraduate restorative dentistry (14);

- e-portfolios supporting the development of reflective practitioners (15); and

- blended approaches supporting inquiry-based learning $(16,17)$.

Such learner-centred approaches contribute to improvement of analytic and reflective thinking and are being embedded within curriculum designs to stimulate deep rather than surface approaches to learning (18). As a relatively new field, opportunities abound not only in e-learning curriculum initiatives in dentistry that respond to the demand for technology-based education to increase student access and flexibility (19) but also for systematic research in the field (20).

\section{Project background: Online peer review in Operative Dentistry}

In taking up the wider challenge to more closely integrate educational technologies with pedagogy (7), a cross-Faculty project was established amongst dental faculties in the Universitas 21 (U21) network of higher education institutions. A key conceptual argument for the project was to move into a different sphere of blended learning with staff and students interacting through distributed networking across sites and institutions $(9,10)$. Essentially, the International Peer 
Review (IPR) project has three components:

1. Professional Identity (introduction): Students develop a professional profile in a letter of introduction;

2. Learning Portfolio/ Assignment: Working locally in their various dental institutions, students develop an assignment (powerpoint) providing an evidence-based discussion and personal critique of their progress over time on a self-selected simulated restorative procedure;

3. Peer-review: Students across institutions are randomly allocated to secure, dedicated online communities of approximately 6-8 students where they post their introductions and assignments and undertake online peer reviews in BLOG format over a common 6-week period.

The dedicated platform developed for the project (diastemas.net) was designed to build international professional communities through the blogging network. It is envisioned that the project will move from the current seven institutions to a more extensive global coverage.

The case study presented here is of one Faculty's involvement with the IPR initiative. For the local curriculum team, the project was seen as advantageous in capitalising on the Faculty's current blended learning initiatives such as the incorporation of both stand-alone and distributed applications of concept mapping software (17) and the integration of interactive whiteboards (IWBs) into problem-based learning (16). In enhancing deeper student learning in Operative Dentistry, the project's focus on presenting, reflecting and critiquing simulated restorative work aimed to challenge students in a surgical skills-based unit of work to move into higher levels of critical thinking (21-23) whilst supporting the necessary initial focus on technique development. This was achieved by introducing students to a portfolio-style, process-oriented assignment early in the curriculum and incorporating peer review to promote critical inquiry. Additionally, the international focus of the project was attractive, not only in terms of meeting university goals for internationalisation and building international networks but more importantly in the opportunity to address key issues raised by the global movement of oral healthcare professionals (24). While the incorporation of an off-campus, international experience is manageable in the faculty's final 
year 'capstone' experience, the inclusion of international opportunities with students early in their degree programme is more difficult. The 'virtual exchange' of an online project therefore provided an avenue for international engagement without the heavy costs, both monetary and in valuable curriculum time, of physical exchange.

\section{Implementation of blended learning in undergraduate dental education: A case study}

The dental programme in this case is an English-medium of instruction programme in an Asian university. The graduates are conferred with the degree of Bachelor of Dental Surgery (BDS). The teaching of operative techniques is introduced in the second year of the five year (now six year) programme. The faculty's involvement in the international project began as an exploratory process in 2008-09 with selected first-year undergraduate students and key academic staff registered as observers during the final phase of online BLOG exchanges. Feedback indicated that both saw the immediate advantage of examining similar clinical problems from different perspectives and in different contexts. This echoed other studies in blended learning in higher education where increased motivation was not only found amongst students but also amongst teaching staff $(2,7)$. Since 2009, this Faculty has been engaged in four full implementation rounds

of the International Peer Review (IPR) project. In-house evaluation in 2010, 2011 and 2012 was conducted in parallel with the wider project evaluation. Presented below are findings from a single case of one dental faculty's project experience. The key research questions addressed are:

1. How did students perceive learning in the IPR project as meeting university learning outcomes?

2. How did student perceptions of learning change in response to curriculum re-design?

While the three IPR components outlined above applied to all cohorts, key refinements were made for improved local implementation during these three years of iterative evaluation and implementation. These local initiatives included:

1. Changes to curriculum timing

a. additional sessions for assignment preparation and tutor feedback (2010 
onwards)

b. scheduling of one additional tutorial session for assignment presentations (2011-2012 onwards);

2. Improved staff development

a. formal staff briefings/ induction outlining project goals and sharing exemplars of student work across all three components (2010 onwards)

3. Procedure selection for assignments

a. Faculty allocated in 2009-2010;

b. Tutor group elected from a selection of 3 possible procedures (2010 onwards);

4. Learning support

a. Two commissioned workshops on academic dentistry (2010 onwards);

5. Online BLOG progress tracking

a. Email reports to supervisors and students on participation rates (2010 onwards);

6. Commencement of a formal BDS II mentorship program with practising dental professionals in the community (2011 onwards)

Additionally, cross-institutional improvements were made to the systems of communication within the diastemas community including automatic email alerts for BLOG postings (2010 onwards).

\section{Materials and Methods}

The case study approach is well documented within the social sciences, particularly within education (25-26) and provides emic insights into the educational experience under examination. In particular, the study has drawn on Yin's (27) approach to case design drawing on both quantitative (survey) and qualitative (focus group) data to support triangulation.

\section{Participants}

On annual IPR project completion, three cohorts (2008-09, 2009-10, 2010-11) of secondyear Bachelor of Dental Surgery (BDS) were invited to participate in the evaluation. Participation was voluntary and ethical approval was obtained prior to commencement of the study. In 2010, 29 
questionnaires were completed online with a response rate of (58 \%). In 2011 and 2012, the survey was administered as a pen-and-paper questionnaire in class with higher response rates $(96 \%(\mathrm{n}=51)$ and $100 \%(\mathrm{n}=54)$ respectively). Between 5-9 students participated in the annual focus group interviews held one-two weeks following the completion of questionnaires. As all BDSII students were considered appropriate informants, focus group participation was by convenience sampling through student self-section as per ethical guidelines. The three cohorts were considered generally comparable given similar admission processes and University quotas for entry pathways with $\sim 70$ $\%$ direct entry via local school system (majority English-medium schools) and $\sim 30 \%$ non-local entry via international schools or first-degree holders (majority English-medium). Cross-group composition ensured multiple BLOG community experiences therefore providing different online experiences and perspectives for discussion.

\section{Analysis of survey data}

The questionnaire was distributed in the week immediately following the final closing of the peer review BLOG period (6 weeks). It consisted of original project-specific items which were combined with selected, project-relevant standardised University items from an annual institutional survey evaluating first- and final-year students' learning experiences (28). Data and analysis reported in this paper is drawn from a sub-set of 16 items on achievement of educational outcomes and the teaching and learning environment from the larger 5-point $(1=$ strongly disagree to $5=$ strongly agree) Likert-scale institutional student survey. For this evaluation, each category consisted of 1-2 project-relevant items. A multivariate logistic regression was performed by pooling the data into a 3 point scale as there were minimal responses at the two opposite ends of the 5-point scale. Therefore, the responses for 'strongly disagree' and 'disagree' were combined to a single 'disagree' and similarly, responses in 'agree' and 'strongly agree' were pooled together to one 'agree'. The multivariate logistic regression was performed at the item level using SPSS software and is reported against aim-related categories (see Table 1). Analysis was conducted on three levels. First, cumulative significance across years was measured to gauge 'overall' significance (see Table 1). Second, the first evaluation cohort (2009-2010) (second year of project implementation) was used as a control group to compare the difference between ensuing years (see Table 1). 


\section{Ethnographic data}

In addition to the questionnaire data, annual focus-group interviews were conducted to gain more specific insights into student perceptions of the effectiveness of this innovation for their clinical learning. The rationale for adopting a focus group rather than individual interview approach was based on collective familiarity with the project and the "uncontroversial nature" of the interview schedule (29). The interviews were semi-structured with a core set of questions asked of all participants; however, the interviewer was free to explore students' responses through planned and spontaneous probe questions (Appendix 1) which were open-ended and divergent in nature to elicit detailed responses and elaborations. Additionally, open exchange was fostered by drawing on the principles of stimulated recall (30) through the large-screen sharing of various IPR community interactions with the focus group via an interactive white board.

The interviews were video-recorded and transcripts were analysed thematically drawing on the principles of grounded theory $(31,32)$ as themes and codes were derived from the data and gathered into explanatory categories and concepts; however, using a constructivist approach was taken (33) with data collection occurring simultaneously with inductive analysis. This iterative approach informed a quality-enhancement cycle so that feedback from each focus group informed improvements in subsequent IPR implementation whilst simultaneously refining research inquiries. The data presented below is drawn from second-tier analysis of 'focused coding' (34) using the 10 University aims as themes and exploring item-level areas of significance identified by the survey analysis.

\section{Results and Discussion}

Descriptively, more than half of the students at the beginning of the evaluation agreed that they were: able to look at things from different perspectives (item $4-55 \%$ ) and to evaluate their academic strengths and weaknesses realistically (item 7 - 59\%). They also agreed that on completing the project, they were more aware of personal strengths and weaknesses (item $8-52 \%$ ), able to see things from a global perspective (item $11-55 \%$ ) and to communicate effectively with others (item $12-52 \%$ ). Lower perceived project gains (disagree) at initial evaluation were: development of in-depth knowledge (item 1 - 28\%), sharpening of analytic skills (item 3 - 24\%); stimulating enthusiasm for learning (item 5-28\%); learning to negotiate with others in coming to 
a decision (item $14-29 \%$ ); feeling a part of a group of students and teachers who are committed to learning (item $15-28 \%$ ) as shown in table 1 .

The results of the multivariate logistic regression analysis of all the three years according to the items with frequency of response, parameter estimates, standard error, odds ratios along with the $95 \%$ C.I of the OR and their P Values are presented in Table 1. For cumulative analysis of 'overall' significance across the three years of the evaluation, there were significant improvement for items 1 (developed in-depth knowledge, $\mathrm{P}=0.002$ ); 6 (developed life-long learning skills, $\mathrm{P}=0.001$ ); 9 (seeing things from others' points of view $\mathrm{P}=0.001$ ); 10 (understanding of other cultural backgrounds, $\mathrm{P}=0.015$ ) and 16 (discussed topics of broader intellectual issues, $\mathrm{P}=0.042$ ).

[Table 1. Multivariate logistic regression analysis]

Comparatively, when using the 2009-10 class as a reference group, major significant (See table 1 for P-values and 95\% CI) cohort effects were found involving self-reports of: (a) developing in-depth knowledge (item 1, OR=2.9, for the second cohort and $\mathrm{OR}=5.7$ for the third cohort) which shows a sustained increase over the years but no significance between the second and third cohort, (b) developing analytical skills (item $3, \mathrm{OR}=2.53$ for the third cohort only when compared to the first cohort), (c) developing skills enabling lifelong learning (item 6, OR=6.66 for the third cohort) which is a large increase given that there was no significant difference between the first and second cohort ( $\mathrm{OR}=4.65$ between second and third cohort), (d) awareness about personal strengths and weaknesses ( $\mathrm{OR}=2.57$ between second and third cohorts), (e) seeing things from another person's point of view (item 9, $\mathrm{OR}=5.04$ for the second cohort and $\mathrm{OR}=6.15$ for the third cohort) which also shows increase over the years but no significance between the second and third cohort, (f) understanding people of different ethnic/cultural backgrounds (item 10, $\mathrm{OR}=3.8$ for the third cohort) with significant effect between the second and third cohort also $(\mathrm{OR}=2.25)$, (g) global perspective (item $11, \mathrm{OR}=2.55$ between the second and third cohort only) (h) communicating ideas professionally (item $12, \mathrm{OR}=2.66$ for the third cohort) with no significance between the second and third cohort and (i) discussing topics of intellectual interest with teachers and students (item $16, \mathrm{OR}=2.67$ for the third cohort) with significant effects between the second and third cohorts $(\mathrm{OR}=2.44)$. 
These results are further discussed in the light of qualitative data and are examined under three areas: impact, engagement, and internationalisation. The closing discussion considers notions of social context and learning in understanding the socio-cognitive relevance for student learning processes of inquiry-based designs such as the International Peer Review (IPR) project.

\section{Impact}

Item 6 under the Aim C Lifelong Learning and item 9 under Aim E Greater understanding of others had the greatest initial impact as they were highly significant $(\mathrm{P}$-value $<0.001)$ in comparison with the 2009/2010 control year. This is positive considering that key project goals were to support students in developing professionalism and expanding understanding of different viewpoints. Students in the 2011-12 focus group noted how differences across countries stimulated peer discussion:

Yes, it actually stimulates us to learn more about the procedure that we are doing, because we can see that different countries, they have different approaches to doing the same thing, and then because they might have their rationale behind, and we have our rationale behind. (FG2012, S3)

With regard to lifelong learning, students in focus group discussions perceived direct relevance to understanding the principles of evidence-based dentistry. They also saw a learning trajectory beyond the IPR project and their undergraduate studies towards their future clinical work with patients:

I think the general trend for dentistry is implementing like the evidence-based dentistry, so everything - you need to have scientific evidence. It's not just like what the practitioner thinks it's right to do it. But you also need to obtain like how the general perspective in the world of dentistry is thinking of this procedure. And also, like, you need to have, it's training you to collect evidence so that you can have a stronger base when you explain to a patient. So I think in this term, in this way, it is good. (FG2012, S3) 
Additionally, students were encouraged to appreciate the relevance of establishing and maintaining professional network relations for their careers:

I think concerning about the lifelong learning, because we might, in the future practice, we may have the chance to have conferences with other dentists, and we may have to share ideas with other dentists. (FG2012, S3)

The growth over time in positive student perceptions with regard to item 1 in Academic/ Professional excellence (Aim A) may indicate the permeating curricular philosophy of evidencebased, academic dentistry and the benefit of enhancements in the form of specific workshops in academic dentistry that also supported professionalism and appropriate peer review in blogging. This improvement may also have been influenced by the in-house refinements in implementation with students given greater flexibility in assignment topic selection after feedback from the first experience in 2009-10:

It certainly encourages excellence but then we focused too much on Class II, not so much other restorations. (FG2010, S1)

Feedback and confidence in implementation encouraged a shift from the coordinator assigned model to a group-based selection in consultation with tutors ( 3 procedures per group). This may also have contributed to the significance noted for Aim E where the ability to discuss presentations within their in-house groups during assignment preparation supported students in becoming more receptive towards critique before undertaking the global exchange.

In terms of Learning communities (Aim J), the following description of exchanges in one group's BLOG interactions illustrates the dynamic involved in communicating online over time:

Oh, he also asked the, something about our school - how often we use a certain technique, like bonding amalgam. And then basically I just reply and then explain the reason why I chose to use like a flat plastic to break the marginal ridge for the project I was working on. Then he goes and he says after reading the book I agree with you etc. And after that, I say 
oh yes, and then he will try the technique next time on a patient. OK, I will look forward to hearing from you soon. (FG2011, S5)

Whilst qualitatively positive impact is registered, ongoing maintenance of a learning community of practice in such a collaborative project remains a key challenge for project leaders (9).

\section{Engagement}

Statistical results indicate improvement in student perceptions of the IPR project over time (see Table 1). Certainly, motivation improved as students and staff became more familiar with the tasks and process. Whilst potentially intimidating, the sharing of student assignment work was seen as a positive, motivating factor (Item 5). In interviews, Student 4 (2012) attributed this to the peer review process:

I do think that it does motivate me to do some research because the project would be seen by other people. (FG2012, S4)

The incorporation of in-house workshops and online resources in academic dentistry included analysis of exemplars from consenting senior students. This additional level of shared expectations regarding the quality of student work may also have provided inspiration. For the case school, the additional public profile the project achieved at both faculty and University teaching and learning presentations and publications may have also contributed to sustaining motivation for both staff and students.

The academic aspects of the project were also seen as motivating with a student in the second cohort perceiving this as enhancing personal confidence in performing operative techniques:

Because you are reading literature about such as restoration, so I guess you feel a little more confident in doing it. (FG2011, S1) 
Both items under Critical intellectual inquiry (Aim B) were rated positively across the three years with some gain made in item 3 (analytic skills). The reflection by the student below indicates how online BLOG engagement supported peer critique:

He knows how I use my instrument to break my ridge and he's so interested. He tried it and tried it but didn't like it. He went back and said, "I don't know why you use that, can you clarify that?" He said, "It's a good way too, but you should try this way as well." (FG2011, S5)

Additionally, a student in the following year considered the entire learning experience as inquiry-based rather than direct transmission:

It introduced a new way to learn I think, I try to look at other's prepare, their presentation and I try to appreciate the differences. This is the kind of way for you to learn. It's like a, we learn the way how we should learn, not just a way of learning the facts. (FG2012, S3)

The teaching and research team felt that the additional academic rigor demanded when students were justifying their preparation in partnership with the supervised technical training exercises was, indeed, promoting critical thinking skills. Indeed, the quality and content of focus group interviews indicated that students were engaged in critical self-reflection:

In certain procedures I need to re-do it, may be aware of the weakness that I have done, then I try to improve it, show some progress. I think it is a good way for me to learn...more aware like. The reason for doing each step, for example, like why I should do baffling on a side like on a restoration, what is the reason behind? Because we need to, for every procedure, we need to have rationale behind to post on the presentation, right? So we need to actually find references, try to quote things before you proceed to the other step. So I think it's a good way of learning. (FG2012, S3)

The relatively poor rating along with the cumulative and contrastive lack of significance for both items under Aim I Collaboration was perplexing for the teaching and research team given 
the peer review aspect and the strong curriculum design focus on learning communities. However, the following student reflection on assignment development may offer some insights:

I think that it is really like doing individual stuff mainly, so collaboration is a minor part. So, when we look at the assignment, we naturally approach in this way, like present the good PowerPoint and then, when people may suggest you, like, adopt the ideas or different research, so I think collaboration is a minor part. (FG2012, S4)

Related to collaboration is the key project aim of creating a network to support global thinking amongst highly internationalised universities. Internationalisation and global citizenship, however, proved more challenging concepts for analysis.

\section{Internationalisation}

As a global project, the relatively low improvement over time in perceptions of achieving global citizenship (Aim G) were specifically addressed by focus groups in 2011 and 2012:

Sorry, Ijust think that this global thinking is not something that you can necessarily achieve in just one IPR project. I think it's something that you have to like, you have to sort of build up over the years. (FG2011, S1)

While the project was distinctly recognized as 'international', these second year students were cautious to identify it as aligning with 'global citizenship' which was perceived as a more nebulous and lofty concept:

I think it is kind abstract to measure about global citizenship... Global citizenship seems like a really big term like it means like on an international conference or something. (FG2012, S3)

Student understandings of the items themselves may have contributed to perceptions and scores. While Intercultural understanding registered improvement in the final year of the evaluation, it still proved a difficult concept for students. They grappled with seeing a connection 
between this construct and a peer review project in Operative Dentistry, despite its international dimension:

Before, like, we have to share our ideas with each other, and you know how they do the, perhaps do the restoration in a different way, but it is interesting to know that. There is some, we discuss some of the controversy about the amalgam and also the composite and I found out that, in those better developed countries, they are now abandoning the - not using the amalgam nowadays and they use, like choose to use the composite. And I bring up the topic like, composite is more expensive and amalgam is cheaper, and so maybe you have to think in a way that amalgam can use in other like for a rural country, it is a better choice of material, so that, yeah, I think this kind of intercultural sharing is interesting for me. (FG2012, S5)

For Student 5 above, 'intercultural sharing' is seen in terms of global economics rather cultural understanding. Indeed student movement beyond institutional settings is a complex issue in health sciences education (35) and more may need to be done to support students thinking in terms of multicultural and multilingual interactions (36).

Student perceptions have informed project evaluation and ongoing modification to project and curriculum design; however, they have also highlighted key issues related to learning theory, particularly with respect to the context of learning.

\section{Learning in the IPR: Reflections from learning theories}

Socioculturalists have a keen interest in how the social context becomes critical to the learning process. For the IPR in Operative Dentistry, the Vygotskian (37) principle of the zone of proximal development is highly relevant. The core premise is that, by engaging with an expert in the field, the novice becomes inducted into a community of practice and gains not only the requisite knowledge and skills of the task, but is also inducted into domain-specific ways of knowing and becoming. In the first stage of the project, students as novice clinicians are guided closely by expert clinical tutors within their institutional settings to begin acquiring the requisite knowledge and skills for their selected operative procedures. The online learning communities then provide 
students with self-critiqued samples of peer-devised work reflecting on personal success in achieving the desired final design. Further novice-expert discussions then occur during and after the online blogging in learning communities leading to further inquiry with knowledgeable others, including, in this case, both clinical tutors and practice-based mentors. As the professional mentorship programme is launched at this point of the curriculum, it was of interest to note that IPR debate topics then became points of discussion with mentors. The formal and informal noviceexpert interactions (see Figure 2) across the IPR community of practice (9) can be seen as contributing towards inducting students into their professional identities as dentists.

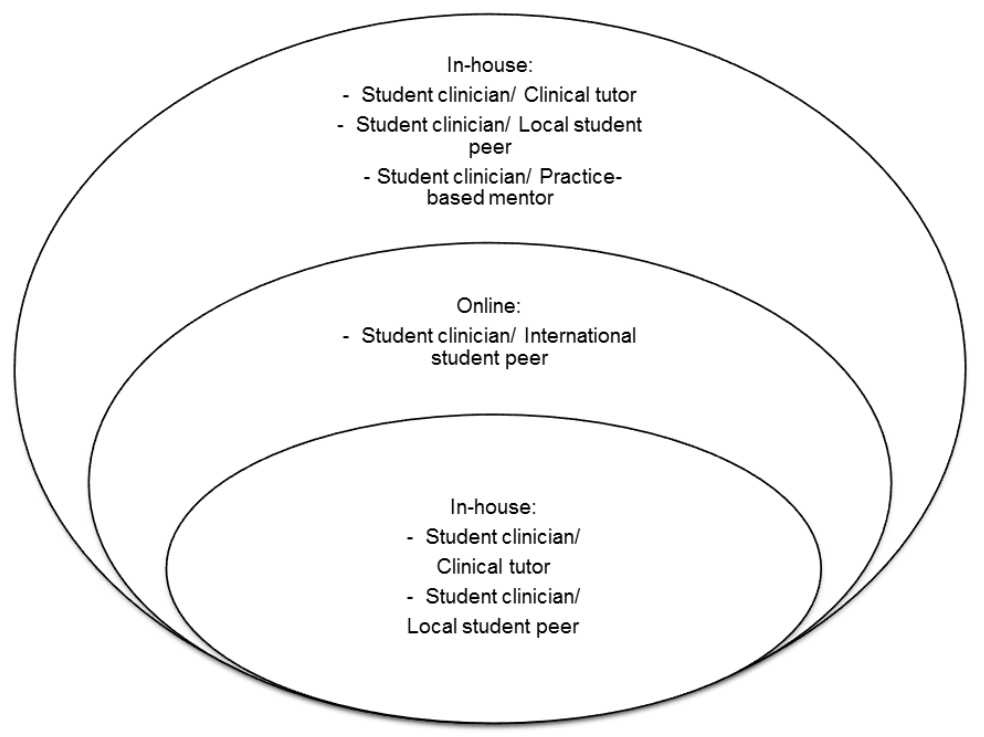

Figure 2 Novice-expert relations in the IPR

\section{Limitations}

The study's limitations are acknowledged in terms of sample size given each cohort consisted of approximately 55 students and focus group sizes ranged between 5-9 students. Online survey response rates in the first year were lower and so comparisons with pen-and-paper results need to be considered with caution. One focus group was invited per annum, but group composition was across multiple peer review groups enabling multiple perspectives.

\section{Challenges and recommendations}

Across the evaluation data, students showed less concern for technical issues related to website design and functionality, although these are recognised by project leaders as core to successful implementation. What was evident to student intellectual engagement with the project was the key 
role of their situated learning communities in supporting cognition, including clinical skill development. The area of global citizenship and intercultural understanding are challenging concepts for educational research with results indicating the need for greater investigation in these areas. Pedagogic challenges for academics and their students in introducing blended approaches to the incorporation of educational technologies (2) were also evident in this case study in dental education. These included adjusting workloads, managing time in class and during independent learning, and familiarising with new technologies. An additional challenge for curriculum designers for such an international collaboration included aligning curricula to establish a window of opportunity for the students to conduct the learning exchange and seeking ongoing funding for project sustainability. Students responded positively when project design and implementation provided: (a) increased flexibility in assignment selection; (b) improved resourcing with online guides and exemplars as well as workshops in academic dentistry and clinical photography. As this is a case study of one school's participation, future research across all participating schools is recommended.

\section{Conclusions}

This evaluation of one dental Faculty's experience of an international collaboration (38) in an international community of practice $(9,10)$, addressed two key research questions: How did students perceive learning in the IPR project as meeting university learning outcomes? How did student perceptions of learning change in response to curriculum re-design? Results indicate that the inquiry-based, process-oriented assignment combined with international peer review supported student engagement and synthesis of knowledge to enhance the acquisition of clinical techniques (21-23). Dental students perceived benefits where cognitive challenge within an evidence-based philosophy occurred in tandem with psychomotor skill development.

This evaluation supports the assertion that the blending of educational technologies within higher education curricula must be a thoughtful and principled inclusion that embeds such technologies within curriculum design to enhance pedagogy and learning outcomes. Evaluation of one case study within the overall IPR community has shown students perceived enhancement to their learning specifically in Operative Dentistry and, more generally, in meeting the larger institutional goals that support preparation of university graduates to engage with an 
interconnected and rapidly changing global landscape. The project evaluation indicates the usefulness of sustained evaluation of over time when implementing and refining an educational intervention. Global collaborations are highly encouraged by institutions; however, they need careful monitoring and ongoing support for success. For members of this international project, however, the developmental work was seen as worthwhile in supporting student learning outcomes in dental education. 


\section{Acknowledgements}

The authors gratefully acknowledge seed funding from The Universitas 21 Health Sciences (Dentistry) group for web design and faculty development and The University of Hong Kong for a Teaching Development Grant to support this evaluation. Thanks go to the dedicated international network which sustains the IPR and to the undergraduate students who inspired its development and agreed to participate in this evaluation. We also wish to thank Ms Rita Suen Po Chu for research assistance and Dr Lisa Cheung for materials development.

\section{List of abbreviations}

BDS: Bachelor of Dental Surgery

IPR: International Peer Review project

HKU: The University of Hong Kong

UBC: The University of British Columbia

\section{Appendix 1 Open-ended Interview Guide}

The focus group interview format will be open-ended using stimulated response, thinkaloud protocols. That is, the staff and students will view student postings to the International Peer Review website platform and comment on student learning.

The interviewer may ask simple additional prompts to explore points raised during the course of the interviews such as:

- What are the students doing/ thinking there? Why did they do/think this?

- How are they being 'global citizens'?

- What do you notice regarding global clinical competencies?

- What comments would you make regarding design and organisation of the IPR project? 


\section{References}

1. Kirsh D. Problem Solving and Situated Cognition. In: Robbins P, Aydede M, editors. The Cambridge Handbook of Situated Cognition. Cambridge: Cambridge University Press; 2009. p. 264-306.

2. Vaughan N. Perspectives on Blended Learning in Higher Education. International Journal on E-Learning. 2007;6(1):81-94.

3. Arabasz P, Baker MB. Evolving Campus Support Models for E-Learning Courses. EDUCAUSE Centre for Applied Research. 2003.

4. Masie E. The Blended Learning Imperative. In: Bonk CJ, Graham CR, editors. Handbook of blended learning: Global perspectives, local designs. San Francisco, CA: Pfeiffer; 2006.

5. De George-Walker L, Keeffe M. Self-determined blended learning: a case study of blended learning design. In: Soliman I, MacDonald I, editors. Higher Education Research \& Development. Milperra, Australia: Routledge; 2010. p. 1-13.

6. Cook DA, Garside S, Levinson AJ, Dupras DM, Montori VM. What do we mean by webbased learning? A systematic review of the variability of interventions. Medical Education. 2010;44(8):765-74.

7. Bonk CJ, Kim K, Zeng T. Future directions of blended learning in higher education and workplace learning settings. In: Bonk CJ, Graham CR, editors. Handbook of blended learning: Global perspectives, local designs. San Francisco, CA: Pfeiffer; 2008.

8. Bridges S, Botelho M, Green JL, Chau ACM. Multimodality in problem-based learning (PBL): An Interactional Ethnography. In: Bridges S, McGrath C, Whitehill TL, editors. Problem-based learning in clinical education: The next generation. Dordrecht: Springer 2012. p. 99-120.

9. Gardner K, Bridges S, Walmsley D. International peer review in undergraduate dentistry: enhancing reflective practice in an online community of practice. European Journal of Dental Education. 2012;16(4):208-12.

10. Gardner K. An Online Community of Inquiry for Reflective Practice in an Operative Dentistry Course. Journal of Dental Education. 2012;76(5):641-50.

11. Gleeson C. Education beyond competencies: a participative approach to professional development. Medical Education. 2010;44(4):404-11. 
12. Khatami S, MacEntee MI. Evolution of Clinical Reasoning in Dental Education. Journal of Dental Education. 2011;75(3).

13. MedEdPortal. Peer Review Overview. Washington, DC: Association of American Medical Colleges; 2010 [cited 2011]; Available from: http://services.aamc.org/30/mededportal/servlet/segment/mededportal/login/Peer+Review ers/

14. Robinson PB, Lee JW. The use of real time video magnification for the pre-clinical teaching of crown preparations. British Dental Journal. 2001;190(9).

15. Gwozdek AE, Springfield EC, Peet MR, Kerschbaum WE. Using Online Program Development to Foster Curricular Change and Innovation. Journal of Dental Education. 2010;75(3).

16. Bridges SM, Botelho MG, Tsang PCS. PBL.2.0: Blended learning for an interactive, problem-based pedagogy. Medical Education. 2010;44(11):1131.

17. Bridges SM, Dyson JE, Corbet EF. Blended learning, knowledge co-construction and undergraduate group work. Medical Education. 2009;43(5):490-1.

18. Prosser M, Trigwell K. Understanding Learning and Teaching: The Experience in Higher Education. Philadelphia: Open University Press; 1999.

19. Grimes EB. Use of distance education in dental hygiene programs. Journal of Dental Education. 2002;66(10).

20. Bridges S, Whitehill TL, McGrath C. The next generation: Research directions in PBL. In: Bridges S, McGrath C, Whitehill TL, editors. Problem-based learning in clinical education: The next generation. Dordrecht: Springer 2012. p. 225-31.

21. Anderson LW, Krathwohl DR, Airasian PW, Kathleen A, Cruikshank KA, Mayer RE, et al. A Taxonomy for Learning, Teaching, and Assessing: A Revision of Bloom's Taxonomy of Educational Objectives: Addison Wesley Longman Inc.; 2001.

22. Miller GE. The assessment of clinical skills/competence/performance. Academic medicine. 1990;65(9):S63.

23. Newble DI, Entwistle NJ. Learning styles and approaches: implications for medical education. Medical Education. 1986;20(3):162-75. 
24. Corbet E, Akinwade J, Duggal R, Gebreegziabher G, Hirvikangas H, Hysi D, et al. Staff recruitment, development and global mobility. European Journal of Dental Education. 2008;12:149-60.

25. Shulman LS. "Just in case..." Reflections on learning from experience. In: Colbert J, Trimble K, Desbert P, editors. The case for education: Contemporary approaches to using case methods. Massachusetts: Allyn \& Bacon; 1996.

26. Stake R. Case studies. In: Denzin NK, Lincoln YS, editors. Handbook of qualitative research. 2nd ed. Thousand Oaks: Sage; 2000.

27. Yin RK. Case study research: Design and methods. California: Sage; 1994.

28. Webster BJ, Chan WSC, Prosser MT, Watkins DA. Undergraduates' Learning Experience and Learning Process: Quantitative Evidence from the East. Higher Education 2009;58(3):375-86.

29. Morgan DL. Focus groups as qualitative research. 2 ed. Thousand Oaks, CA: Sage; 1997.

30. Gass SM, Mackey A. Stimulated recall methodology in second language research. Mahwah, New Jersey: Lawrence Erlbaum Associates; 2000.

31. Miles M, Huberman A. Qualitative data analysis: A source of new methods. London: Sage; 1994.

32. Strauss AL, Corbin JM. Basics of qualitative research: techniques and procedures for developing grounded theory. Thousand Oaks: Sage Publications; 1998.

33. Charmaz K. Grounded theory: Objectivist and constructivist methods. In: Denzin N, Lincoln Y, editors. Handbook of qualitative research 2nd ed. Thousand Oaks: Sage; 2000. p. 509-35.

34. Charmaz K. Grounded theory. In: Smith A, editor. Qualitative psychology: A practical guide to research methods. London: Sage; 2003. p. 81-110.

35. Roberts C, Daly M, Kumar K, Perkins D, Richards D, Garne D. A longitudinal integrated placement and medical students' intentions to practise rurally. Medical Education. 2012;46(2):179-91.

36. Bridges S, Yiu CKY, McGrath C. Multilingual interactions in clinical dental education: A focus on mediated interpreting. Communication \& Medicine. 2011;8(3):197-210.

37. Vygotsky LS. Mind in society: The development of higher psychological processes. Cambridge: Harvard University Press; 1978. 
38. O'Sullivan PS, Stoddard HA, Kalishman S. Collaborative research in medical education: a discussion of theory and practice. Medical Education. 2010;44(12):1175-84. 